\title{
An Explanation for Internet Use Obstacles Concerning E-Learning in Iran
}
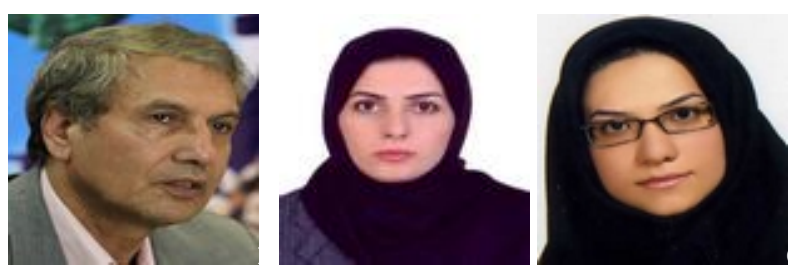

Ali Rabiee ${ }^{1}$, Zahra Nazarian ${ }^{1}$, Raziyeh Gharibshaeyan ${ }^{2}$

1Payame Noor University, Iran, ${ }^{2}$ Allameh Tabatabaee University, Iran

\section{Abstract}

E-learning is advancing in Iran right now. The Iranian higher education system is applying electronic learning in order to conquer the limitations of the existing education system. These limitations include the growing number of applicants for entering universities, lack of classrooms for education, and universities' tensions in replying to these needs. Also, ease of access to e-learning and a lack of financial resources are reasons for applying e-learning in Iran. In addition, the Iranian higher education system wants to progress with global changes in the information era and they see it as necessary to acquire information and knowledge. Meanwhile, web technology enjoys a special and significant role. This paper investigated barriers to using internet technology for elearning in the Iranian context. The methodology employed both qualitative and quantitative techniques. In the qualitative stage, exploratory observations of eight virtual institutes for higher education and interviews with 20 experts in these institutes were used. The analysis of the data showed that socio-cultural, structural, educational, economic, and legal factors were the most prominent obstacles to web technology use; each factor comprised a number of components. So as to check the primacy of the factors and the extracted components at large, the researchers developed a Likert-type questionnaire; the questionnaire, which comprised the five types of obstacles and their related components, enjoyed a high degree of validity and reliability. Twenty students in each of the eight institutes were asked to fill out the questionnaire. The analysis of the data showed that socio-cultural factors are the most influential barriers to use of the Internet in e-learning.

Keywords: Internet; e-learning; distance learning; Iran 


\section{Introduction}

The development of information technology (IT), in the last century, has brought about significant changes in many areas including learning and teaching (J erry, 2000). Higher education has not been an exception (Cahill, 2008). In this arena, IT has brought about significant changes to the delivery methodologies in the open university (OU). An OU, which is a distance learning and research university, employs a variety of communications technologies with the aim of giving students the opportunity to study off-campus (Cahill, 2008). In other words, it provides university education to those wishing to pursue higher education on a part-time and/or distance learning basis. In recent years, computers and the Internet have made distance learning distribution easier and faster and have given rise to the virtual university, the entire educational offerings of which are conducted online (Phipps \& Merisotis, 1999). The idea of distance education, which was first promoted in the United Kingdom, has spread over many countries around the world (Carswell \&Venkatesh, 2002).

Fariborzi and AbuBakar say,

In Iran, the number of students is growing faster than the number of public and private universities or any other institutions of higher learning. The Web-based learning is the solution to this problem. However, the current Iranian higher education system faces so many challenges that it is very difficult to achieve the effectiveness of Web-based learning. (2011, p. 59)

Along with the significant advancements in distance education or e-learning in many parts of the world, considerable improvements can be observed in Iran's higher education system (Kamalian \& Fazel, 2009; Rahmanpoor, Liaghatdar, \& Afshar, 2008; Safavi \& Mohammadi, 2007). The large youth population and growing demand for acquiring higher education in Iran (Araste, Sobhaninejad, \& Homaie, 2009; Emadzade, 2009; Ghavidel, Farjadi, Razeghi, \& Badiei,2012; Iran's National Education Report, 2006; Roushan, 2009) create a condition wherein replying to the need for e-learning is not only replying to an educational need but also to a social need. A lack of classrooms, the flexibility of time and place for education, access to multi-media resourses, the ease of updating information, and the growing number of applicants for higher education are reasons to increase online access to education in Iran. Studies show that acceptance of e-learning from Iranian students in comparison to traditional learning is advancing with high speed especially in higher education.

Though such movements are worth appreciating, one cannot ignore the main obstacles to providing web-based distance education in developing countries, in general, and in Iran, in particular, due to economical, social, political, and cultural factors. The present study was conducted to identify the main obstacles to providing online distance education and to provide a number of suggestions to help remove the obstacles. In 
comparison to other research in Iran, our study is more complete in some ways and takes a careful look at the subject. The five components discussed in this study are not found in others. Further, in comparison to studies conducted in other developing countries, we can say that different countries have different cultures. In the authors' view, although this study has some common points with studies in other developing countries, there are differences. The authors could not find resources relating to the subject of this article other than the ones described below, because of limitations in Iran as far as access to research and the Internet.

\section{Review of the Literature}

According to Farajollahi et al. (2010) Morss and Murray mention that the most important mission of higher education from the beginning has been to give information, knowledge, and skills to students (2005, p. 5). But higher education is at the beginning of a revolution regarding information and communication power. In another article Miguel and Pherson (cited in Farajollahi et al., 2010) say that today universities should educate those who have the ability in grouping, analyzing, and combining information, problem solving skills, communication skills, discussion, and verbal, technological and management skills, instead of preserving and saving data, to be able to adjust themselves to rapid social and industrial changes (2004, p. 78).

Umrani-Khan and Iyer (2009, p. 1) believe that

use of technology to facilitate learning is accepted as a value across educational institutions. However, the focus is still largely on getting the infrastructure and creating the e-learning content. It is necessary to consider the individual factors that play an important role in the adoption of e-learning. For example, attitude of students and teachers towards e-learning may affect their acceptance of the technology in the teaching learning process. The four determinants of e-learning acceptance are performance expectancy, effort expectancy, social influence and facilitating conditions.

E-learning was first coined by Cross and refers to any kind of learning which is mediated through the use of the Internet and an intranet (Atashak, 2007). Examples of e-learning are web-based teaching, web-based learning, internet-based teaching and advanced learning (Khan, 2005; Yaghoobi, Malekmohammadi, Irvani, \& Ataran, 2008). Cooper (2004) defines e-learning as the set of training activities employing audio, visual, computer, and networking electronic devices. In his definition of e-learning, Mayer (2005) views e-learning as an active kind of learning which changes teaching and learning processes dramatically and plays a significant role in developing information 
and communications technology. In a more comprehensive definition, Murthy and Mathur (2008) define e-learning as incorporating all educational activities that are carried out by individuals or groups working online or offline and synchronously or asynchronously via networked or standalone computers and other electronic devices. More recently, Hamdi (2007) defines e-learning as using web technology for planning and delivering lessons and providing a learning environment for monitoring teaching and learning activities.

Many advantages for e-learning have been put forward by a number of scholars. Pawlowski (2006), for instance, believes e-learning can help overcome geographical and individual limitations which are typical of traditional educational systems. In other words, by providing off-site educational opportunities, e-learning offers the possibility of flexibility to accommodate the many time-constraints imposed by personal responsibilities and commitments. Accordingly, learners can study wherever they have access to a computer and the Internet. They can join discussions in the bulletin board threaded discussion areas at any hour, or visit with classmates and instructors remotely in chat rooms.

Such flexible access to information and resources has also been acknowledged by Naidu (2006); he appreciates distance learning for giving learners, who are generally adults in full or part-time employment, the opportunity to study at a time and place that is convenient. This way, distance education frees learners from the constraints of conventional residential educational settings since they are not required to attend lectures in locations away from where they may be living and working.

Besides removing constraints of time and place, distance learning provides learners with self-paced learning modules which allow them to work at their own pace. In fact, learners have the option to select learning materials that meet their level of knowledge and interest. Here, different learning styles are addressed and facilitation of learning occurs through varied activities (Solution for international schools, n.d). Other merits like providing equal and free opportunities to access and search through courses, improving the quality of teaching training methods, and reducing the demand on educational resources and institutional infrastructure such as buildings have also been acknowledged by Geogieva, Todorov, and Smrikarov (2003) and Pawlowski (2006).

Despite interest in e-learning, it is not free from flaws. Among the constraints to using e-learning, one can refer to the lack of access to the technology infrastructure or not having knowledge of how to use it. Another limitation can be the costs of hardware and software, costs of infrastructure support and its maintenance, and related costs that are factored into the deployment of an e-learning venture (Naidu, 2006). Besides these disadvantages, e-learning has other limitations in developing countries like Iran: Low motivation of the students and instructors in virtual learning and teaching, lack of staff knowledge of the technology, and lack of proper management and expert human resources are among the basic problems when implementing virtual education in Iran (Maneie, 2003). 
It does not mean, however, that no attempts have been made in Iran to promote elearning opportunities. Distance education based on e-learning has attracted much attention in recent years due to the emphasis of the country's Fourth Development Program (based on Wisdom) on improving elearning (Rahmanpoor et al., 2008). Accordingly, increasing numbers of universities are becoming interested in providing virtual educational opportunities to the students in different academic fields. Shiraz University was the first institution which provided virtual education, but in only one study area, in 2004 (Safavi, Bavaghar, \& Ghafari, 2007). This trend was later continued by Science and Industry University, Amir-kabir and Khaje-nasir Industrial Universities. Other institutions like Shahid Beheshti, Qom and Esfahan Industrial universities are making the final preparations for providing virtual distance education to their students (J afarpoor, Fayyazi, \& Bahrahzadeh, 2008). Despite such attempts, one should not ignore serious obstacles to using e-learning that might hinder further efforts in the field.

\section{Methodology}

This field study is conducted on two levels: quantitative and qualitative. In the first step in order to find out the obstacles facing the research, we conducted an interview with 20 professors and specialists who were executives of e-learning in Tehran. It should be said that the participants were selected in a non-random and targeted way. Throughout the interview at first we explained the general goal of the research and then the questions. Then we brought up the relevant questions. Considering the limitation of the target population, we investigated different aspects of the subject through deep interviews and the content analysis method, text analysis, and we elicited five obstacles, economical, cultural and social, legal and legitimate, educational, and structural. In the second step, we designed a 26-question questionnaire with the help of acquired components (with $0.86 \%$ Cronbach's alpha coefficient and confirmed reliability by a specialist) with five Likert-type variables. In each institution, we asked 20 M.A. students of different majors, such as Information Technology and E-commerce, Administration and MBA, Commercials and Media, totalling 160 people, to answer the questionnaire. After conducting the questionnaire, we extracted the raw data of the research and formulated it in a general information table. Then the information was analyzed in SPSS and with the help of the Freidman test. In an interview phase, at first we explained the general goal of the research then asked the relevant questions. In the questionnaire phase, also, we explained the necessary points written on the questionnaire form to the respondents, and when the respondents were answering the survey, we were present to answer their questions. 


\section{Results}

According to 20 theses guided by the first author of the study and several studies conducted by the first two authors, as well as previous research, reference studies, and the results of an interview with well-known university professors in this field, there are five obstacles.

Results of the study are presented in different sections: First, the primacy of the five obstacles is reported and next the importance of each component within the extracted obstacles is presented.

\section{Primacy of obstacles.}

Table 1 summarizes the level of importance of each one of the five obstacles for questionnaire respondents in percentages.

Table 1

Primacy of the Five Obstacles

Obstacles Unimportant $\begin{gathered}\text { Of little } \\ \text { importance }\end{gathered} \quad \begin{gathered}\text { Moderately } \\ \text { important }\end{gathered} \quad$ Important $\begin{gathered}\text { Very } \\ \text { important }\end{gathered} \quad$ Total

\begin{tabular}{|c|c|c|c|c|c|c|c|}
\hline 1 & $\begin{array}{l}\text { Socio- } \\
\text { cultural }\end{array}$ & 5 & 8 & 16.7 & 25 & 43.3 & 100 \\
\hline 2 & Structural & 5 & 10 & 26.7 & 23.3 & 35 & 100 \\
\hline 3 & Educational & 3.33 & 13.33 & 28.3 & 30 & 25 & 100 \\
\hline 4 & Economic & 5 & 15 & 33.3 & 30 & 16.7 & 100 \\
\hline 5 & Legal & 8.3 & 13.3 & 36.7 & 25 & 16.7 & 100 \\
\hline
\end{tabular}

Freidman statistics proved that there was a statistically significant difference in the significance respondents attached to different obstacles: $\mathrm{x} 2=15.99, \mathrm{p}=.003, \mathrm{df}=4$. Also, it was found that the socio-cultural obstacle is viewed to be the main barrier to implementing e-learning; legal barriers, on the other hand, were found to be the least significant among the five. 


\section{Socio-cultural obstacles.}

Freidman statistics also showed that there was a statistically significant difference between the seven components of the socio-cultural obstacle: $\mathrm{x} 2=33.8, \mathrm{p}=.000, \mathrm{df}=$ 7. Table 2 indicates the ranking of the components based on responses to the questionnaire. As the table shows pessimism of the government toward the Internet was selected with highest frequency by the respondents.

In Iran and other developing countries, the government and other responsible institutions in this field have an authoritative and pessimistic view toward cyberspace. This condition becomes worse in relation to universities and other higher educational institutions. Previous studies revealed that the government has a very high tendency to interfere with university affairs (Rabiee \& Nazarian, 2012a; Winter; 2012b).

Table 2

Ranking of the Seven Components within the Socio-Cultural Obstacle

\section{Components}

Mean

rank

1

Pessimism of the custodians toward the Internet global network

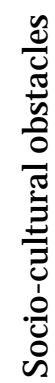

2

Lack of national preparation and determination to launch online training

3 Perceived lack of efficiency of online training compared with traditional methods of instruction

4 Custodian's willingness to impose limitations on using the Internet

$5 \quad$ Students' willingness to participate in classes

6 Students' concern over perceived lack of socialization associated with virtual universities

7 Lack of public familiarity with virtual education 


\section{Structural obstacles.}

Freidman statistics also showed that there was a statistically significant difference between the four components of the structural obstacle: $\mathrm{x} 2=70.8, \mathrm{p}=.000, \mathrm{df}=3$. Table 3 indicates the ranking of the components based on responses to the questionnaire. As the table shows inappropriate telecommunication infrastructure in the country was selected with highest frequency by the respondents.

Table 3

Ranking of the Four Components within the Structural Obstacle

\section{Components}

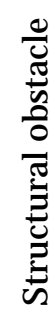
country level

1 Inappropriate telecommunication infrastructure in the

2 Poor coordination for using the Internet at the international

3 Learners' need for having access to the Internet

4 Lack of preparation of institutions

\section{Educational obstacles.}

Freidman statistics also indicated that there was a statistically significant difference between the six components of the educational obstacle: $\mathrm{x} 2=21.99, \mathrm{p}=.001, \mathrm{df}=5$. Table 4 indicates the ranking of the components based on responses to the questionnaire. As the table shows resistance of a number of faculty members to online training was selected with highest frequency by the respondents.

Table 4

Ranking of the Six Components within the Educational Obstacle

1 Resistance of a number of faculty members to online training 
3 Lack of sufficient familiarity of the students with search tools

Lack of necessary training of the teachers and lecturers from educational institutions

$5 \quad$ Problems with practical and laboratory courses

6 Low record of virtual education in the country

\section{Economic obstacles.}

Freidman statistics also showed that there was a statistically significant difference between the four components of the economic obstacle: $\mathrm{x} 2=35.2, \mathrm{p}=.000, \mathrm{df}=3$. Table 5 indicates the ranking of the components based on responses to the questionnaire. As the table shows the high expense of studying in virtual universities for the students was selected with highest frequency by the respondents.

Table 5

Ranking of the Four Components within the Economic Obstacle

Components

Mean

rank

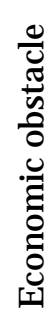

High expense of studying in virtual universities for the

students

Lack of interest of private sectors in investing in virtual

education

3 High costs of administering online training for the institutions

4 Lack of adequate financial support of the government

\section{Legal obstacles.}

Freidman statistics also indicated that there was a statistically significant difference between the three components of the legal obstacle: $\mathrm{x} 2=16.9, \mathrm{p}=.000, \mathrm{df}=2$. Table 6 shows the ranking of the components based on responses to the questionnaire. As the table shows lack of compliance with international norms and standards of using the Web was selected with highest frequency by the respondents. 
Table 6

Ranking of the Components within the Legal Obstacle

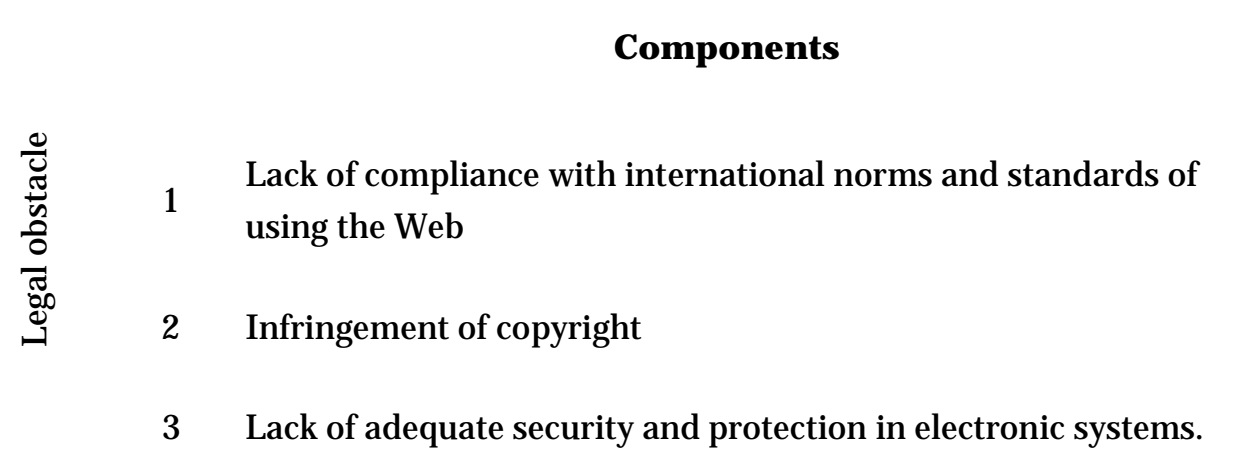

Mean

rank

3 Lack of adequate security and protection in electronic systems.

\section{Conclusion}

The present study was conducted in order to find the obstacles facing the use of the Internet in the process of e-learning in a developing country like Iran. The results show that decision makers are not unified in respect to the cultural and political consequences of Internet use and this results in a lack of trust in using the Internet for educational purposes, so using the Internet for different aspects in Iran is actually facing a delay. To cite an example, we observe a judgement of unreliability regarding e-journals and elearning courses. Also, studies show that people who volunteer to participate in electronic education are those who don't succeed in entering the state universities; thus, choosing such an option for them isn't considered a need for e-learning but only an option to continue their higher education. On the other hand, some believe that Iranians' face-to-face and oral culture is an obstacle to e-learning in the country. Furthermore, in developing countries, techniques, communication, and telecommunication foundations are few and this can also be considered an obstacle for elearning. Also, developing countries like Iran are facing different international boycotts; consequently, they do not have enough capacity to develop e- learning.

According to Feyzi and Rahmani (2003) and Kamalian and Fazel (2009) and Mosavi et al. ( 2011), another obstacle for elearning in Iran is that learners do not have easy access to computers with the appropriate hardware, software, or connectivity to the Internet. On the other hand, cultural, structural, and economical barriers actually turned into educational barriers. As far as professors and persons in charge of educational affairs, no mental readiness for the higher educational system and a lack of basic education relating to e-learning lead to difficulties in the use of communication technologies, so are considered to be obstacles to e-learning. According to the results found through deep and qualitative interviews with specialists, e-learning is not 
widespread in elementary and high schools, students and professors are not familiar with e-learning, and learners do not have enough information about e-learning, all of which lead to serious difficulties related to making the culture and structures for elearning. The results of the research confirm that students and learners do not have enough knowledge of and enough skill in e-learning. The results accord with the study by Seyed Naghavi (2007). On the other hand, the results of the present study show that one of the most important factors in e-learning is previous experience with using and searching the Internet. This accords with the study results of Mahdizadeh et al. (2008). Furthermore, e-learning in the higher educational system in Iranian universities isn't free of charge and this is another obstacle for e-learning in the country. Also, different policies in the higher educational system are obstacles for the private sector to participate in e-learning education and this decreases competition.

According to the results of this study and considering the conditions of the country, the following suggestions are recommended. We need to say that these suggestions are substructure solutions that are ordered in accordance with the results of this research and other findings.

- First, it is recommended that online training courses be offered to students with no fees in public universities.

- It is offered that online training courses be available to students from the very early stages, possibly from primary school; this results in students' familiarity with online training and might lead to public acceptance of virtual learning. To achieve this aim, we need to train students on how to use computers and search engines. Not only students but also instructors and staff need to be familiar with online training courses.

- It is suggested that development of virtual universities be stipulated in the country's national policy. Also, it is recommended that strict training policy be implemented in virtual universities; this way the credibility of virtual university degrees will increase.

- We need to offer e-learning in elementary schools. In order to do this, it is necessary to introduce the concepts of the computer and information technology as a foundation for e-learning in the future.

- The government should consider enhancing the communication skills of students, like writing and sending emails, doing searches, writing for blogs, and so on in order to become an essential part of the country's programs.

- Another solution is to place e-learning educational units in the Ministry of Education and the Ministry of Health and Treatment and to improve universities that have the capacity to change into e-learning universities; this capacity is now present at Payam Noor University. Also, the 
government should educate instructors and students to become ready to accept e-learning. Another suggestion is to promote the validity of academic documents of e-learning.

- Decreasing the cost of e-learning courses and getting financial help to improve e-learning courses, as well as educating instructors and students about e-learning, are other suggestions for developing e-learning in the country.

- Appropriate organization of educational resourses and materials, ease of access to the materials, and appropriate educational content play an important role in conducting these courses. Thus, it is better to consider proper material and content before conducting e-learning courses.

- E-learning courses should complement traditional teaching and should be held mutually with well-known local and foreign universities.

- Removing unnecessary legal limitations on using the Internet will make it easier to accept e-learning courses.

- The validity of the academic documents of e-learning courses is under question from official organizations in Iran. So necessary action should be taken in order to give the same value to e-learning courses as other traditional courses. 


\section{References}

Atashak, M. (2007). Theoretical and empirical foundations of e-learning. Quarterly J ournal of Research and Planning in Higher Education, 13(1), 135-156.

Araste, H., Sobhaninejad, M., \& Homaie, R. (2009). Students' evaluation of universities in Tehran in the era of globalization. Quarterly J ournal of Research and Planning in Higher Education, 14(4), 47-66.

Carswell, A. D., \&Venkatech, V. (2002). Learner outcomes in asynchronous distance, education environment. International J ournal of Human-Computer Studies, 56, 494- 975.

Cahill, R. (2008). What motivates faculty participation in e-learning: A case study of complex factors (Doctoral dissertation). University of St. Thomas, St. Paul, MN.

Cooper, R. (2004). E-learning in the world. London, England: Falmer.

Emadzade, M.(2009). Financial support of higher education concerning the government and private. Articles collection on new approaches in higher education (pp.95122). Cultural and Social Research Studies of Technology, Research and Science Ministry.

Farajollahi, M., Zare, H., Hormozi, M., Sarmadi, M. R., \&Zarifsanaee, N. (2010). A conceptual model for effective distance learning in higher education. Turkish Online J ournal of Distance Education, 11(3). Retrieved from http:// www. tojde.anadolu.edu.tr/tojde39/articles/article_2.htm

Fariborzi , E., \&AbuBakar, K. (2011). E-learning in Iran: Looking at effectiveness via a qualitative study. Paper presented at the International conference on humanities, society and culture, Singapore. IPEDR , 20, 58-63.

Feyzi, K., \& Rahmani, M. (2004). Problems and solutions of e-learning in Iran. Quarterly J ournal of Research and Planning in Higher Education, 10(3), 99120.

Geogieva, G., Todorov, G., \& Smrikarov, A. (2003). A model of virtual university - some problems during its development. Proceeding of the $4^{\text {th }}$ International Conference on Computer Systems and Technologies: E-learning (pp.709-715). Bulgaria: ACM Press.

Ghavidel, S., Farjadi, G., Razeghi, H., \& Badiei, H.(2012). Forecasting of higher education demand for undergraduate and graduate levels in Iran's 2025 
prospect. Quarterly J ournal of Research and Planning in Higher Education, 18(1), 43-68.

Hamdi, M. S. (2007). A multi-agent approach to information customization for the purpose of academic advising of students. Applied Soft Computing, 7, 746-771.

Iran's national higher education report (2006). Institute for research and planning in higher education.Tehran, Iran.

J afarpoor, M., Fayyazi, M., \& Bahrahzadeh, M. M. (2008). An investigation of the factors influential in the development of virtual universities. Paper presented at the fifth international conference on communications and information technology, Tehran, Iran.

J erry, B. (2000). The e-learning potential. Retrieved from http:// www.kdgonline.com/ webpages/ whitepapercontent2.htm

Kamalian, A., \& Fazel, A. (2009). On the feasibility of e-learning. Educational Technology, 4(1), 13-27.

Khan, B.H. (2005). Managing e-learning: Design, delivery, implementation and evaluation. Hershey, PA: Information Science Publishing.

Mahdizadeh, H., Bieman, H., \& Mulder, M. (2008). Determining factors of the use of elearning environments by university teachers. Computers and Education, 51(1), 142-154.

Maniei, R. (2003). Improving distance education in higher education. Rahyaft J ournal, 31, 43-53.

Mayer, R. (2005). IT for education. Oxford, UK: Oxford.

Miguel, B., \&Mcpherson, M. (2004). Developing innovation online learning. London, England: RoutledgeFalmer.

Montazar,G. A.(2005). Challenges and approaches of information development of higher education system in Iran. Paper presented at the electronic learning conference (pp.101-145), Zanjan, Iran.

Morss, K., \& Murray, R. (2005). Teaching at university: A guide for postgraduates \& researchers. New Delhi, India: Sage Publication.

Mousavi, M., Mohammadzade nasrabadi, M., \& Pezeshki-Rad, G. R. (2011). Identifying and analyzing buffer and inhibitor factors for implementation and development 
of e-learning in Payame Noor University. Quarterly J ournal of Research and Planning in Higher Education, 17(1),137-154.

Murthy, C. S. H. N., \&Mathur, G. (2008). Designing e-learning programs for rural social transformation and poverty reduction. Turkish Online J ournal of Distance Education, 9(1). Retrieved from http:// tojde.anadolu.edu.tr/tojde29/ pdf/article_11.pdf

Naidu, S. (2006). E-learning: A guidebook of principles, procedures and practices. New Delhi, India: Commonwealth Educational Media Center for Asia. Retrieved from http:/ / www.giz.de/ Themen/ en/ dokumente/ en-e-learning-guidebook.pdf

Omidnia, S., Masrom, M., \&Selamat, H.(2011). Review of e-learning and ICT infrastructure in developing countries (case study of Iran). American J ournal of Economics and Business Administration, 3(1), 120-125.

Pawlowski, T. (2006). Information technology and education. Leads: Kork.

Phipps, R. A., \& Merisotis, J . P. (1999). What's the difference? A review of contemporary research on the effectiveness of distance learning in higher education. Washington, DC: Institute for Higher Education Policy.

Rabiee, A., \& Nazarian, Z.(2012a, Winter). Factors influencing higher education policies with an approach to article 44 of the constitution. Strategy, 61, 247-276

Rabiee, A., \&Nazarian, Z.(2012b, Spring).Obstacles to the privatization of higher education in Iran and presentation of appropriate strategies for their removal. Iranian Higher Education Quarterly J ournal, 4(2), 171-206

Rahmanpoor, M., Liaghatdar, M., \&Afshar, E. (2008). Improving e-learning in higher education: Obstacles and solutions. Paper presented at the fifth international conference on communications and information technology, Tehran, Iran.

Roushan, A.R. (2009). Privatization of high education in Iran. Deputy of research Islamic azad university, Tehran, Iran.

Safavi, A., Bavaghar, M., \&Ghafari, H. (2007). Norms and standards of e-learning materials. Quarterly J ournal of Research and Planning in Higher Education, 13(1), 27-52.

Safavi, A., \& Mohammadi, M. (2007). Credibility of e-learning courses in Iran. Paper presented at the second conference on e-learning, Zahedan, Iran. 
Seyed naghavi, M.A. (2007). Study of teachers and students attitude toward e-learning: Surveying in Iran's e-learning universities. Quarterly J ournal of Research and Planning in Higher Education, 13(1), 159-176.

Solution for international schools in China. (n.d.). In Global Over IP. Retrieved from http:/ / goip.asia/ product.php?t=169

Umrani-Khan, F., \&Iyer, S. (2009, July). ELAM: A model for acceptance and use of elearning by teachers and students. Proceedings of the 4th international conference on e-Learning (pp.1-25). University of Toronto, Canada.

Yaghoobi, J., Malekmohammadi, I., Irvani, H., \&Ataran, M. (2008). Desirable features of students and faculty members involved in e-learning courses in higher education: Students' perspectives. Quarterly J ournal of Research and Planning in Higher E, 14(1), 159-173.

\section{Athabasca University $\mathbf{A}$}

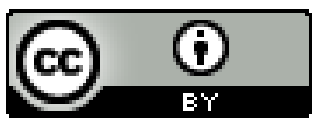

